\title{
Equilibrium Studies of Methylene Blue Dye Sorption by Dried Water Hyacinth Shoot
}

\author{
A. K. Inengite ${ }^{1}$, C. Y. Abasi $^{1} \&$ D. B. Johnny ${ }^{1}$ \\ ${ }^{1}$ Department of Chemical Sciences, Niger Delta University, Wilberforce Island, Bayelsa State, Nigeria \\ Correspondence: A. K. Inengite, Department of Chemical Sciences, Niger Delta University, Wilberforce Island, \\ P.M.B. 071, Bayelsa State, Nigeria. E-mail: ainengit@yahoo.com
}

$\begin{array}{cc}\text { Received: August 12, } 2014 & \text { Accepted: September 2, } 2014 \quad \text { Online Published: September 10, } 2014 \\ \text { doi:10.5539/enrr.v4n4p120 } & \text { URL: http://dx.doi.org/10.5539/enrr.v4n4p120 }\end{array}$

\begin{abstract}
Water hyacinth (Eichhornia crassipies) has proved to be a menace in water bodies and studies are on, in the direction of solving this problem; one of which is to discover economic uses of water hyacinth. Adsorption of heavy metals and dyes from aqueous solutions by activated carbon derived from water hyacinth is one of such studies. In this study, dried and pulverized water hyacinth shoot was used for the sorption studies. This is in the bid of eliminating the rigours of producing activated carbon, thereby saving time and cost. The adsorption capacity of water hyacinth shoot for Methylene Blue dye was studied as a function of initial metal ion concentration in a batch system. Results showed that adsorption increased with methylene blue dye concentration. Seven adsorption isotherms, namely Langmuir, Freundlich, Temkin, Dubinin-Radushkevich, Florry-Huggins, Harkins-Jura and Henry's isotherms were applied to the adsorption data. Isotherm parameters showed that all the isotherms correlated well with the adsorption data. The maximum adsorption capacity of Methylene Blue dye to the dried water hyacinth shoot was found to be $58.14 \mathrm{mg} / \mathrm{g}$. The use of dried water hyacinth shoot would appreciably save the time and cost for producing activated carbon but not without some compromise of efficiency.
\end{abstract}

Keywords: water hyacinth shoot, methylene blue, adsorption isotherms

\section{Introduction}

Water hyacinth (Eichhornia crassipies) is a free floating aquatic plant with inflated petioles. It has been reported to double its number every two weeks by means of off-shoots (Akinyemiju, 1987). It has posed itself as a menace in water bodies and water ways by degrading water quality, reducing light and oxygen diffusion, reduction in water movement/transportation and reduction of dissolved oxygen by its death and decomposition (Nyananyo et al., 2007).

Several researchers have worked and are still working, to proffer solutions to the problems posed by water hyacinth.

The subject of cost effective removal techniques for aqueous pollutants as alternatives to conventional methods is one that continues to draw the attention of researchers. High efficiency, availability and low cost have been major reasons for the use of plants, agricultural and biological materials as adsorbents for aqueous pollutants. Dye effluents in aqueous streams represent another group of water pollutants that require great attention by virtue of the large amount of production and use of dyes globally (Imamura et al., 2002; Kanawade \& Gaikwad, 2011). The reduction of light penetration in water bodies, especially to benthic organisms and the low biodegradability of dyes present them as potential toxicants to marine lives. Mutagenic and carcinogenic effects have also been adduced to untreated water containing dye effluents (Sivaraj et al., 2010). The use of water hyacinth for heavy metals and dye removal from aqueous solution by adsorption is well reported. Low et al. (1995), reported the biosorption of basic dyes (methylene blue and Victoria blue) by water hyacinth roots with maximum sorption capacities of 128.9 and $145.9 \mathrm{mg} / \mathrm{g}$ respectively. Kanawade and Gaikwad (2011) also reported that the adsorption data of methylene blue by water hyacinth roots correlated well with the Langmuir and Freundlich isotherms. Sivaraj et al. (2010), reported the removal of reactive Magenta B and reactive Turquoise Blue dyes using activated carbon obtained from water hyacinth. The results reported show that water hyacinth is a useful material for the removal of dyes in solution.

Other studies considered activated carbon prepared from water hyacinth and the use of dried water hyacinth roots (Soni et al., 2012; Kanawade \& Gaikwad, 2011); Sivaraj et al., 2010; Rajamohan, 2009; Varghese et al., 2004). The use of dried water hyacinth stem and leaves was also studied by El-Wakil et al. (2013), after pretreatment with EDTA and activation with $\mathrm{H}_{3} \mathrm{PO}_{4}$. 
This study however looked at dried water hyacinth shoot, for easy preparation and usability and further correlated the adsorption data with seven different adsorption isotherms, namely: Langmuir, Freundlich, Temkin, Dubinin-Radushkevich, Florry-Huggins, Harkins-Jura and Henry's isotherms.

An infrared (IR) scan of the dried water hyacinth revealed that functional groups like the C-O strectching vibration of cellulose backbone at $1035.6 \mathrm{~cm}^{-1}$ (Ibrahim et al., 2009), equivalent to peak $1020.34 \mathrm{~cm}^{-1}$ in the IR spectrum (Figure 1). Water hyacinth showed broad peaks peak at $3370 \mathrm{~cm}^{-1}$ due to bonded $-\mathrm{OH}$ and peak at $1632 \mathrm{~cm}^{-1}$ assigned to conjugated hydrogen bonded carbonyl groups (Varghese et al., 2004).

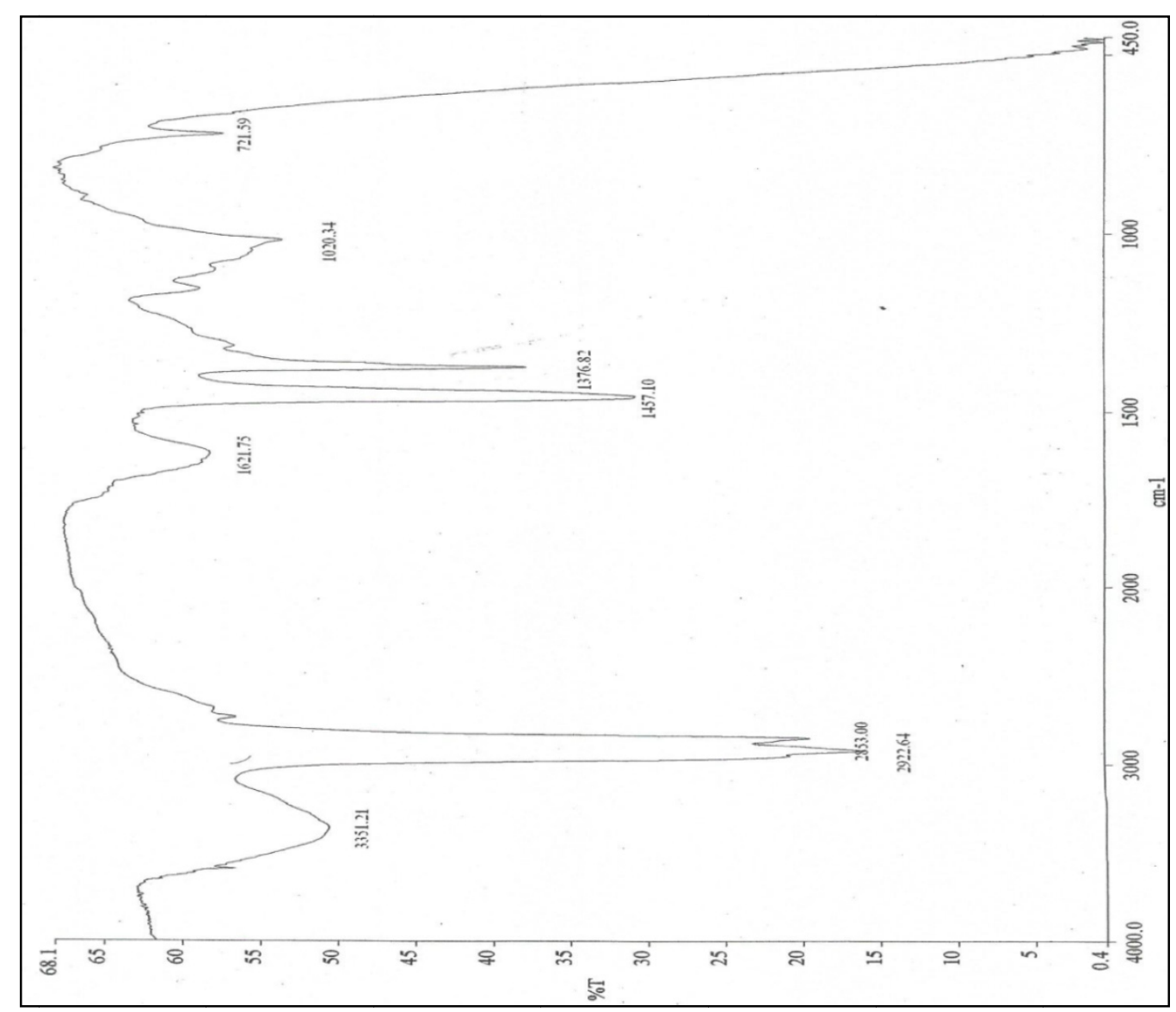

Figure 1. Infrared Spectrum of dried water hyacinth

Having these ionic functional groups on the surface of the dried water hyacinth, which suggest mainly of the hydroxyl groups of a cellulosic material, there is great potential for it to serve as an adsorbent.

The structure of MB dye is as shown in Figure 2. It is an amine with electron rich nitrogen and sulpur atoms.<smiles>CN(C)c1ccc2nc3ccc(=[N+](C)C)cc-3sc2c1</smiles>

Figure 2. Chemical Structure of Methylene Blue Dye

The proposed interactions between the functional groups on the water hyacinth and the MB dye are as illustrated in Figure 3. Co-ordinate covalent bonding and hydrogen bonding are the most probable interactions between the MB dye and water hyacinth. 
<smiles>C[N+](C)=c1ccc2nc3ccc([N+](C)(C)C)cc3sc-2c1</smiles>

Figure 3. Proposed Chemical Interactions between Dried Powered Water Hyacinth Shoot and Methylene Blue Dye

\section{Materials and Methods}

Water hyacinth was collected from the Nun River at Amassoma, Southern Ijaw Local Government Area of Bayelsa state, Nigeria. The water hyacinth was thoroughly washed with clean water and the shoots separated from the roots. The separated shoots were then washed with distilled water, cut into small pieces and oven-dried for about $6 \mathrm{hrs}$ at $110^{\circ} \mathrm{C}$, until a steady mass was obtained. The dried shoots were then ground into a powdery form, using an electric blender (Sonic, Japan) and stored in a plastic bottle.

Methylene Blue (MB) manufactured by Sanaisi reagent Ltd. (Shanghai, China) and supplied by Kem Light Labotatories PVT Limited (Ikeja, Lagos) was bought at a local shop and used as the adsorbate. Distilled water was used for the preparation of all the solutions and reagents.

A stock solution of $500 \mathrm{mg} / \mathrm{l}$ of the MB dye was prepared by weighing accurately $0.125 \mathrm{~g}$ of dye using an electronic weighing balance (FA2104 Asearchtech Instrument) and transferred into a volumetric flask.

Distilled water was then added and the solution stirred until the $250 \mathrm{ml}$ mark was reached. Standards solutions of 100 , 200,250 and $300 \mathrm{mg} / \mathrm{l}$ were prepared by serial dilution. The $\mathrm{pH}$ values of the solutions were adjusted to 7 (neutral) using $\mathrm{NaOH}$ and $\mathrm{HCl}$ accordingly. These standard solutions were used to calibrate a UV-VIS spectrometer (Spectrumlab 752s) at $663 \mathrm{~nm}$, which is the instrument's wavelength of maximum absorption of UV radiation by MB dye.

The surface functional groups on the dried water hyacinth were determined using Fourier Transform Infra-Red Spectrophotometer (FTIR). The IR spectrum obtained is as shown in Figure 1.

\subsection{Experimental Procedure}

In a batch adsorption process, 40mg portions of the dried powdered water hyacinth (adsorbent) was accurately weighed using an electronic weighing balance, and separately transferred into four test-tubes corresponding to four concentrations of 100, 200, 250 and $300 \mathrm{mg} / \mathrm{l} \mathrm{MB}$ solution. $10 \mathrm{ml}$ of each stated concentration of MB solution was then added to each of the four test-tubes. The test-tubes were tightly closed and put on an orbital shaker at $200 \mathrm{rpm}$ for 60 minutes. At intervals of 10 minutes, the supernatant was collected and analyzed for absorbance using the UV-VIS spectrometer at $663 \mathrm{~nm}$. The absorbance reading was taken and the concentration evaluated using the calibration curve. The amount of dye adsorbed $(\mathrm{mg} / \mathrm{L})$ was then calculated by difference. The suitability of the sorption was tested using some isotherms to correlate the data obtained. The amount of dye adsorbed at equilibrium in $\mathrm{mg} / \mathrm{g}$ was calculated using the equation:

$$
q_{e}=\frac{v}{m}\left(C_{0}-C_{e}\right)
$$

All the experiments were carried out at an ambient temperature of $(28 \pm 2)^{\circ} \mathrm{C}$.

\section{Results and Discussion}

The amounts of dye adsorbed at equilibrium $\left(\mathrm{q}_{\mathrm{e}}\right)$ are as stated in Table 1 below. The average time contact for equilibrium to be established was approximately 50 minutes. The $\mathrm{q}_{\mathrm{e}}$ increased with increasing initial concentration $\left(\mathrm{C}_{0}\right)$ and was highest with the highest $\mathrm{C}_{0}$ in this study while the $\%$ removal of $\mathrm{MB}$ dye decreases with increasing concentration and the highest \% removal was $51.1 \%$ at the lowest concentration of $100 \mathrm{mg} / 1$. The volume of MB dye used for the adsorption was $10 \mathrm{ml}$ and the weight of the adsorbent was $40 \mathrm{mg}$. 
Fitting of Langmuir isotherm data showed that the adsorption of MB dye tended to monolayer adsorption and the maximum adsorption capacity of MB dye to the dried water hyacinth shoot was $58.14 \mathrm{mg} / \mathrm{g}$ (Figure 4).

Table 1. Amount of MB Dye Adsorbed at Equilibrium

\begin{tabular}{cccc}
\hline $\begin{array}{c}\text { Initial concentration of } \\
\text { MB dye (mg/l) }\end{array}$ & $\begin{array}{c}\text { Equilibrium concentration } \\
\text { of MB dye }(\mathbf{m g} / \mathbf{l})\end{array}$ & $\begin{array}{c}\text { \% Removal of } \\
\text { MB dye }\end{array}$ & $\begin{array}{c}\text { Amount of MB dye adsorbed } \\
\text { at equilibrium } \boldsymbol{q}_{\boldsymbol{e}}(\mathbf{m g} / \mathbf{g})\end{array}$ \\
\hline $\mathbf{1 0 0}$ & 48.88 & 51.1 & 12.78 \\
$\mathbf{2 0 0}$ & 108.00 & 46.2 & 23.00 \\
$\mathbf{2 5 0}$ & 142.48 & 43 & 26.88 \\
$\mathbf{3 0 0}$ & 181.48 & 39.5 & 29.63 \\
\hline
\end{tabular}

The extent of adsorption of the dye by the adsorbate was estimated with seven isotherms, namely: Langmuir, Freundlich, Temkin, Dubinin-Radushkevich, Florry-Huggins, Harkins-Jura and Henry isotherms. The linearized forms of the equations used were:

1). Langmuir:

$$
\frac{C_{e}}{q_{e}}=\frac{C_{e}}{q_{\mathrm{m}}}+\frac{1}{K_{L} q_{m}}
$$

Where: $\mathrm{q}_{\mathrm{e}}=$ Amount adsorbed $(\mathrm{mg} / \mathrm{g})$ at equilibrium

$\mathrm{q}_{\mathrm{m}}=$ Maximum amount adsorbed $(\mathrm{mg} / \mathrm{g})$

$\mathrm{C}_{\mathrm{e}}=$ Final concentration of dye in solution $(\mathrm{mg} / \mathrm{g})$

$\mathrm{K}_{\mathrm{L}}=$ Langmuir or equilibrium constant for adsorption $(\mathrm{L} / \mathrm{g})$

2). Freundlich :

$$
\ln q_{e}=\ln K_{F}+\frac{1}{n} \ln C_{e}
$$

Where, $\mathrm{K}_{\mathrm{F}}$ and $\mathrm{n}$ are Freundlich constants

3). Temkin :

$$
q_{e}=B \ln A+B \ln C_{e}
$$

$$
\begin{aligned}
& \mathrm{B}=\frac{R T}{b_{T}} \text { and } \mathrm{b}_{\mathrm{T}}=\text { adsorption potential of the adsorbent }\left(\mathrm{Jmol}^{-1}\right) \\
& \mathrm{A}=\text { Temkin isotherm constant }\left(\mathrm{dm}^{3} \mathrm{~g}^{-1}\right), \\
& \mathrm{R}=\text { molar gas constant }=8.314 \mathrm{Jmol}^{-1} \mathrm{~K}^{-1} \\
& \mathrm{~T}=\text { Absolute temperature }(\mathrm{K})
\end{aligned}
$$

Temkin isotherm assumes that fall in the heat of adsorption is linear rather than logarithmic, as implied in Freundlich equation.

4). Dubinin-Radushkevich :

$$
\ln q_{e}=\ln q_{D}-2 B_{D} R T \ln \left(1+\frac{1}{C_{e}}\right)
$$

Where, $B_{D}$ is a constant related to the mean free energy (E) of sorption per mole of sorbate as it migrates to the surface of the adsorbent from infinite distance. 


$$
E=\sqrt{\frac{1}{2 B_{D}}}
$$

$\mathrm{q}_{\mathrm{D}}$ is the Dubinin-Radushkevich isotherm constant related to the degree of sorbate sorption by the sorbent surface or the theoretical saturation capacity. It was applied to estimate the porosity, apparent free energy and the characteristics of adsorption.

5). Florry-Huggins :

$$
\log \left(\frac{\theta}{C_{e}}\right)=\log K_{a}+n \log (1-\theta)
$$

Where $\theta=$ degree of surface coverage

$\mathrm{n}=$ number of metal ions occupying sorption site

$\mathrm{K}_{\mathrm{a}}=$ equilibrium constant of adsorption

$\mathrm{C}_{\mathrm{e}}=$ equilibrium metal ion concentration.

The $\theta$ in the Florry-Huggins equation is obtained from the relation

$$
\theta=1-\frac{C_{e}}{C_{0}}
$$

6). Harkins-Jura:

$$
\frac{1}{q_{e}^{2}}=\frac{B}{A}-\frac{1}{A} \log C_{e}
$$

where,

$$
\begin{aligned}
& \mathrm{C}_{\mathrm{e}}=\text { equilibrium concentration of the dye in solution }\left(\mathrm{mgl}^{-1}\right) \\
& \mathrm{q}_{\mathrm{e}}=\text { amount of dye adsorbed onto the adsorbent }\left(\mathrm{mgg}^{-1}\right)
\end{aligned}
$$

$\mathrm{A}$ and $\mathrm{B}$ are the isotherm constants

Harkins - Jura isotherm assumes the presence of multilayer adsorption with the existence of heterogeneous pore distribution.

7). Henry:

$$
\log q_{e}=\log K_{H}+\log \theta
$$

The plots for the isotherms and the adsorption parameters of the equilibrium models are as shown in Figures 4 to 10 and Table 2 respectively.

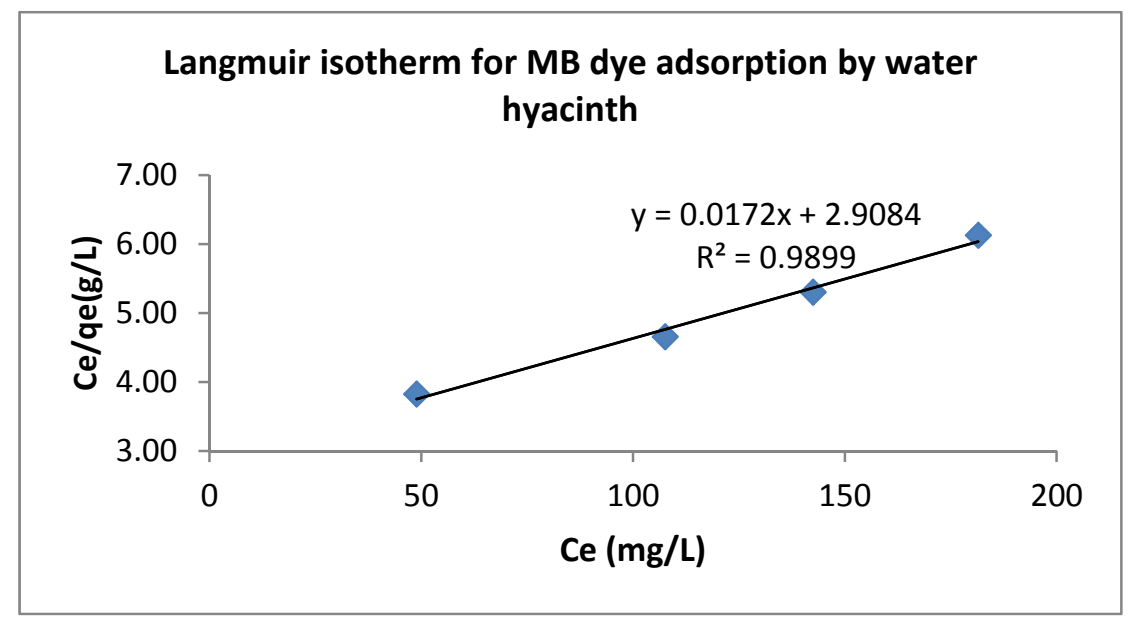

Figure 4. Langmuir isotherm for MB dye adsorption by water hyacinth 


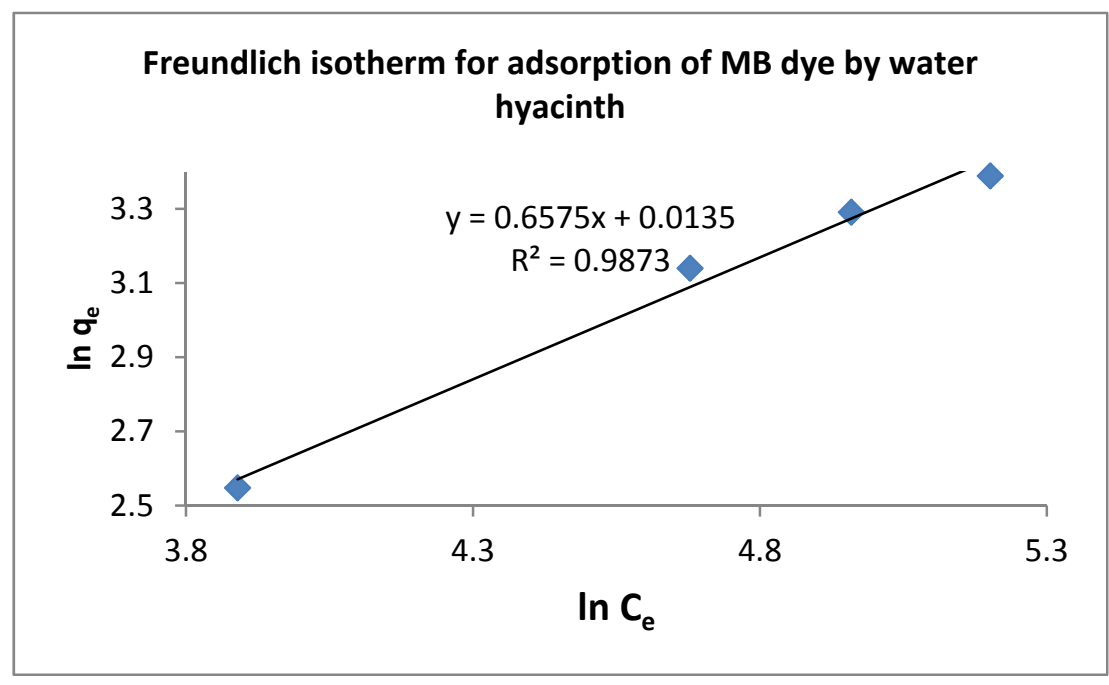

Figure 5. Freundlich isotherm for adsorption of MB dye by water hyacinth

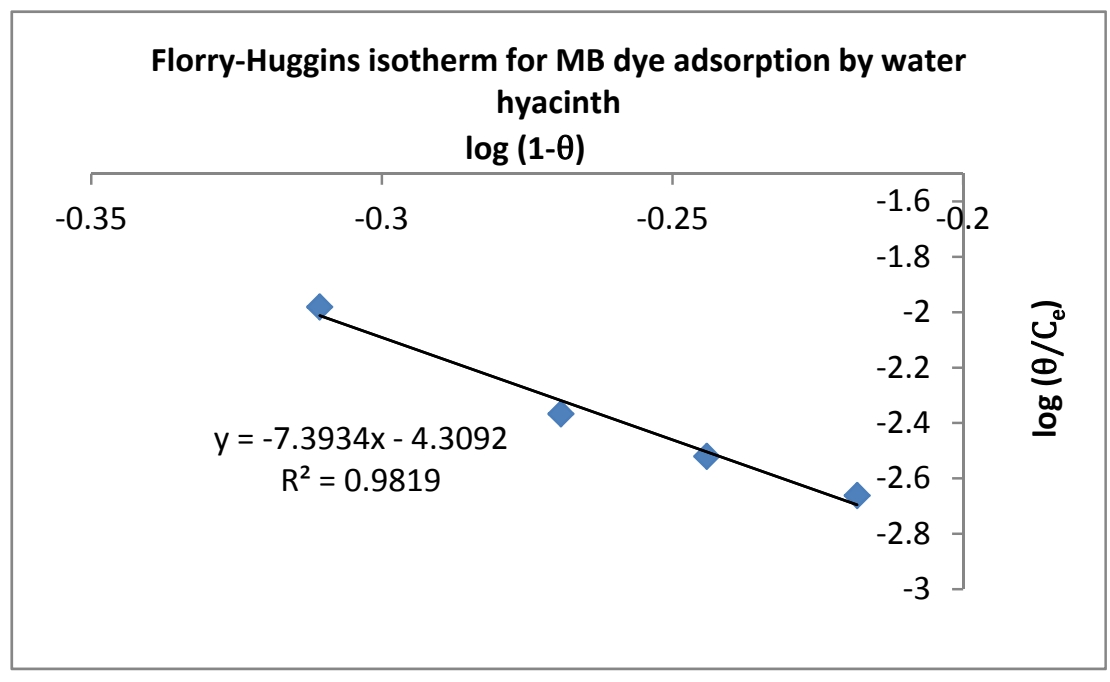

Figure 6. Florry-Huggins isotherm for MB dye adsorption by water hyacinth

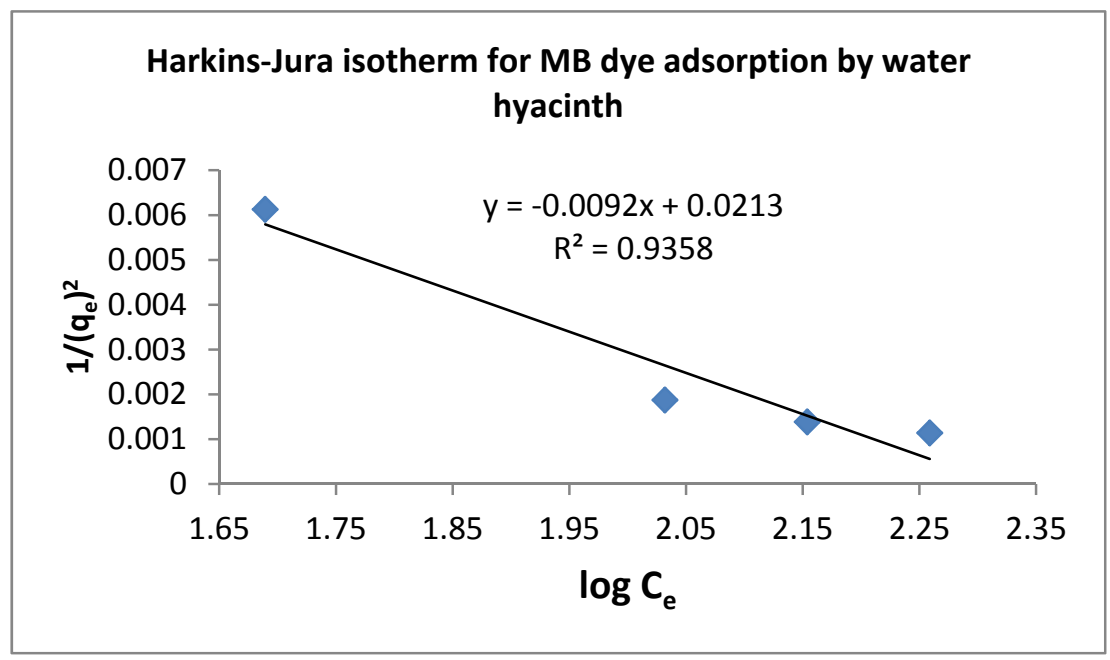

Figure 7. Harkins-Jura isotherm for MB dye adsorption by water hyacinth 


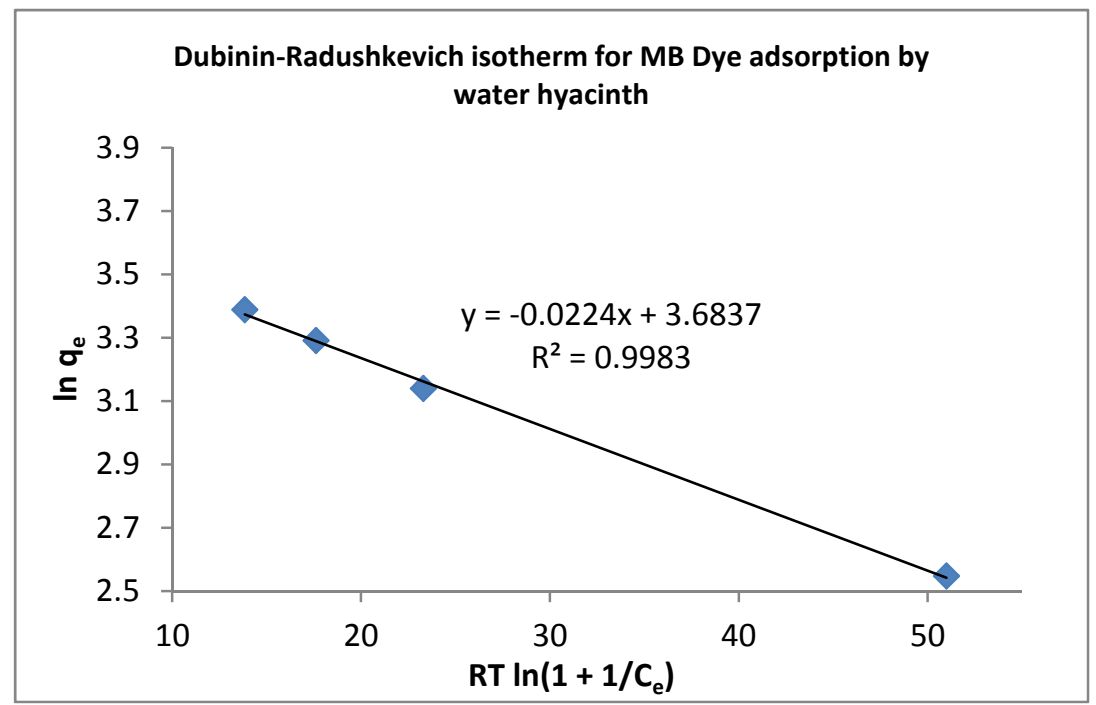

Figure 8. Dubinin-Raduskevich isotherm for MB Dye adsorption by water hyacinth

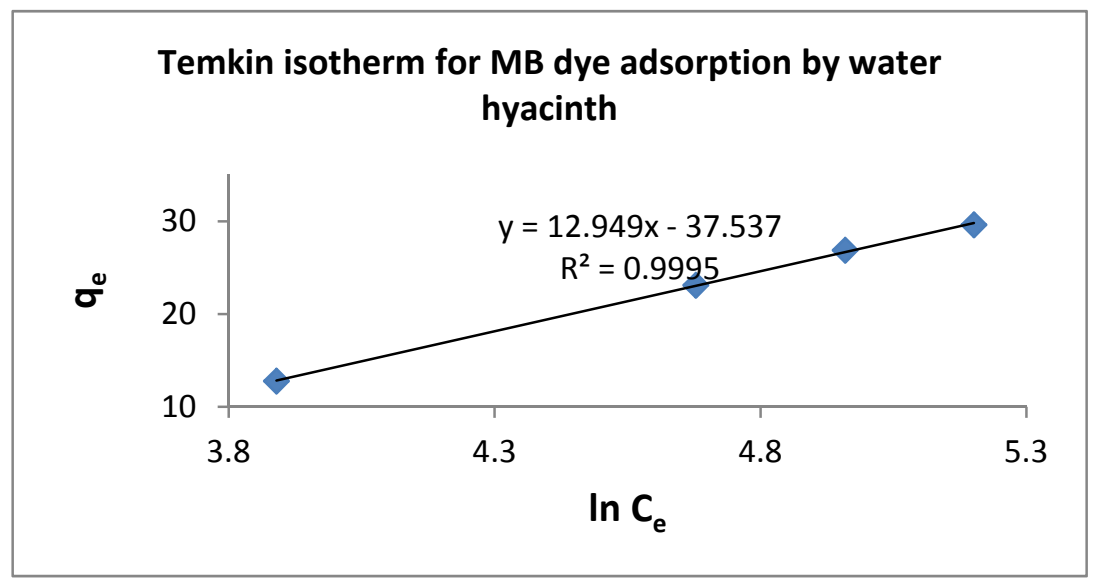

Figure 9. Temkin isotherm for MB dye adsorption by water hyacinth

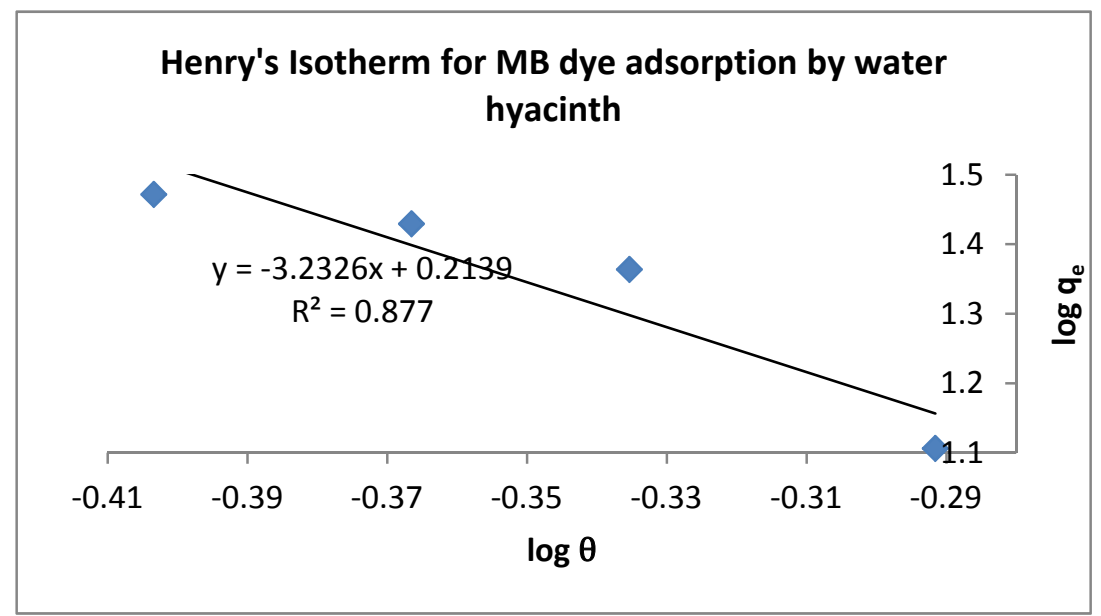

Figure 10. Henry's isotherm for MB dye adsorption by water hyacinth 
Table 2. Isotherm parameters of equilibrium models

\begin{tabular}{|c|c|c|c|c|}
\hline Isotherm & \multicolumn{4}{|c|}{ Isotherm Parameters } \\
\hline \multirow[t]{2}{*}{ Langmuir } & $q_{\max }(\mathrm{mg} / \mathrm{g})$ & \multicolumn{2}{|c|}{$\mathrm{K}_{\mathrm{L}}(\mathrm{L} / \mathrm{g})$} & $\overline{\mathbf{R}^{2}}$ \\
\hline & 58.14 & \multicolumn{2}{|c|}{0.0059} & 0.9899 \\
\hline \multirow[t]{2}{*}{ Freundlich } & $K_{F}(m g / g)$ & \multicolumn{2}{|l|}{$\mathbf{n}$} & $\mathbf{R}^{2}$ \\
\hline & 1.014 & \multicolumn{2}{|c|}{1.521} & 0.9873 \\
\hline \multirow[t]{2}{*}{ Florry-Huggins } & $\mathbf{K}_{\mathbf{a}}$ & \multicolumn{2}{|l|}{$\mathbf{n}$} & $\mathbf{R}^{2}$ \\
\hline & $4.91 \times 10^{-5}$ & \multicolumn{2}{|c|}{-7.393} & 0.9819 \\
\hline \multirow[t]{2}{*}{ Harkins-Jura } & $\mathbf{A}$ & \multicolumn{2}{|c|}{ B } & $\mathbf{R}^{2}$ \\
\hline & 108.70 & \multicolumn{2}{|c|}{2.315} & 0.9358 \\
\hline \multirow[t]{2}{*}{ Dubinin-Radushkevich } & $q_{D}(m g / g)$ & $\mathbf{B}_{\mathrm{D}}\left(\mathrm{mol}^{2} \mathrm{~kJ}^{-2}\right)$ & $\mathrm{E}(\mathrm{kJ} / \mathrm{mol})$ & $\mathbf{R}^{2}$ \\
\hline & 39.7934 & 0.0112 & 6.6815 & 0.9983 \\
\hline \multirow[t]{2}{*}{ Temkin } & $\mathbf{A}(\mathbf{L} / \mathbf{g})$ & B (mg/L) & $\mathbf{b}_{\mathrm{T}}(\mathrm{J} / \mathrm{mol})$ & $\mathbf{R}^{2}$ \\
\hline & 0.0551 & 12.949 & 194.54 & 0.9995 \\
\hline \multirow[t]{2}{*}{ Henry } & \multicolumn{2}{|c|}{$\mathbf{K}_{\mathbf{H}}$} & \multicolumn{2}{|l|}{$\mathbf{R}^{2}$} \\
\hline & \multicolumn{2}{|c|}{1.636} & \multicolumn{2}{|c|}{0.877} \\
\hline
\end{tabular}

The sorption isotherms parameters are shown in Table 2. The isotherm parameters were estimated from the slopes and intercepts of the plots of the sorption variables by linear regression. All the seven isotherms used to fit experimental data gave correlation values that lie between 0.8770 and 0.9995 . The high $\mathrm{R}^{2}$ values indicate the validity of the sorption operations for which these isotherms represent. The best-fitting and the most applicable of the used isotherms are the Temkin and Dubinin-Radushkevich (D-R) with $\mathrm{R}^{2}$ value of 0.9995 and 0.9983 respectively. The linearity of the Langmuir plot and isotherm parameters indicate the occurrence of chemisorption processes. However, the D-R mean adsorption energy (E) value whose magnitude is used in estimating the type of adsorption indicates physisorption (Mufazzal et al., 1999; Abusafa \& Yucel, 2002; Mahramanlioglu et al., 2002; Erdem et al., 2004). From the D-R isotherm, the apparent energy, E, of adsorption was $6.6815 \mathrm{~kJ} / \mathrm{mol}$. Chemisorption processes have been reported to have apparent energy values greater than $40 \mathrm{~kJ} / \mathrm{mol}$ and physisorption lower than $40 \mathrm{~kJ} / \mathrm{mol}$ (Horsfall et al., 2004). The value of $\mathrm{E}$ in this work is indicative of a physisorption mechanism for the MB sorption on to the WH shoot biomass. The Freundlich isotherm parameter, n, indicates the affinity of the sorbent for the sorbate and hence the favourability of the sorption process. According to Kadirvelu and Namassivayan (2000), $\mathrm{n}$ values between 1 and 10 indicates a beneficial adsorption. The $\mathrm{n}$ value of 1.521 implies that the affinity of the WH sorbent for the MB sorbate was favourable. Correlation coefficient for Temkin plot is nearly unity which indicates the suitability of the model for the sorption data as well as the confirmation of the assumption of the isotherm that the fall in sorption heat follows a linear trend instead of a logarithmic one (Sivaraj et al., 2010). The data gives a fair fit for the Harkins-Jura plot and this suggests that multilayer adsorption may not be excluded. The Florry-Huggins isotherm accounts for the degree of surface coverage characteristics of the adsorbate on the adsorbent. The correlation coefficient (0.9819) and the value of $n$ indicate that adsorbate molecules adhered to the surface of the adsorbent. The isotherm was highly applicable to the sorption data. A fair surface coverage of adsorbate particles on adsorbent is further corroborated by the linearity and the correlation coefficient value (0.877) of the Henry isotherm.

The maximum sorption capacities obtained by El-Wakil et al. (2013) were $264 \mathrm{mg} / \mathrm{g}$ for dried water hyacinth stem and $210.5 \mathrm{mg} / \mathrm{g}$ for the dried leaves, while Low et al. (1995) had 128.9 for water hyacinth roots. This study 
recorded a maximum sorption capacity of $58.14 \mathrm{mg} / \mathrm{g}$. The low value of maximum sorption capacity in this study, when compared to studies of El-Wakil et al. (2013) and Low et al. (1995) justifies the relevance of pretreatment and activation of the adsorbent. However, the maximum sorption capacity of this study is comparable to 56.01 $\mathrm{mg} / \mathrm{g}$ obtained by Sivaraj et al. (2010), where pretreatment and activation was not carried out on the adsorbent.

\section{Conclusion}

The report of the study has clearly shown the effectiveness of the water hyacinth shoots for the biosorption of methylene blue dye and the applicability of seven isotherms for the sorption data. The best-fitting and the most applicable of the isotherms used are the Temkin and Dubinin-Radushkevich (D-R). However, there is need to optimize the percentage efficiency by modification or pretreatment of the water hyacinth before preparation as adsorbent. Using the dried water hyacinth without the rigours of preparing activated carbon from it will definitely save time and cost with some compromise to the efficiency.

\section{References}

Abusafa, A., \& Yucel, H., (2002). Removal of ${ }^{137}$ Cs from aqueous solutions using different cationic forms of natural zeolite: Clinoptitolite. Separation Purification Technol., 28(2), 103-116. http://dx.doi.org/10.1016/ S1383-5866(02)00042-4

Akinyemiju, O. A. (1987). Invasion of Nigerian Waters by Water Hyacinth. J. Aquat. Plant Manage., 25, 24-26. http://www.apms.org/japm/vol25/v25p24.pdf

El-Wakil, A. M., Abou El-Maaty W. M., \& Awad, F. S. (2013). Adsorption of Methylene Blue and Rhodamine B from Aqueous Solutions Using Dry or carbonized Water Hyacinth Plant. J. Applied Sciences Research, 9(6), 3607-3619. Retrieved from http://www.aensiweb.com/old/jasr/jasr/2013/3607-3619.pdf

Erdem, E., Karapinar, N., \& Donat, R., (2004). The removal of heavy of metal cations natural zeolites. J. Colloid Interface Sci., 280(2), 309-314. http://dx.doi.org/10.1016/j.jcis.2004.08.028

Horsfall, M., Spiff, A. I., \& Abia, A. A. (2004). Studies on the influence of mercaptoacetic acid (MAA).Modification of cassava (manihot esculeta cranz) waste biomass on the adsorption of $\mathrm{Cu}^{2+}$ and $\mathrm{Cd}^{2+}$ from aqueous solution. Bull. Korean Chem. Soc., 25, 969-976. Retrieved from https://www.google.com.ng/ search?biw $=1366 \&$ bih $=631 \&$ noj $=1 \&$ sclient $=$ psy-ab\&q=Studies + on + the + influence + of + mercaptoacetic + aci $\mathrm{d}+\&$ oq $=$ Studies + on + the + influence + of + mercaptoacetic + acid $+\& g s \_$l $=$serp.3 ...25456.29491.1.30341.7.7.0.0. $0.0 .1130 .1130 .7-1.1 .0 \ldots . .0 .1 \mathrm{1c} .1 .52 . \operatorname{serp} . .7 .0 .0 .9 \mathrm{C} \_$KSoR4cY8

Ibrahim, M., Kuhn, O., \& Scheytt, T. (2009). Molecular Spectroscopic Study of Water Hyacinth Dry Matter. The Open Chemical Physics Journal, 2, 1-6. http://benthamopen.com/tocpj/articles/V002/1TOCPJ.pdf

Imamura K., Ikeda, E., Nagayasu, T., Sakiyama, T., \& Nakanishi, K. (2002). Adsorption behaviours of methhylene blue and its congeners on a stainless steel surface. J. Colloid interface sci., 245, 50-57. Retrieved from http://www.ncbi.nlm.nih.gov/pubmed/16290334

Kadirvelu, K., \& Namassivayan, C. (2000). Agricultural by-products as metal adsorbents. Sorption of lead(II) from aqueous solution onto coir-pith carbon. Envir.Technol., 21, 1091-1097. http://dx.doi.org/10.1080/ 09593330.2000 .9618995

Kanawade, S. M., \& Gaikwad, R. W. (2011). Removal of methylene blue from effluent by using activated carbon and water hyacinth as adsorbent. Int. J. Chem. engineering \& applications, 2(5), 317-319. http://dx.doi.org/10.7763/IJCEA.2011.V2.126

Low, K. S., Lee, C. K., \& Tan K. K. (1995). Biosorption of Basic Dyes by Water Hyacinth Roots. Bioresource Technology, 52, 79-83. http://dx.doi.org/10.1016/0960-8524(95)00007-2

Mahramanlioglu,M., Kizilcikli, I., \& Bicer, I. O. (2002). Adsorption of fluoride from solution by acid treated spent bleaching earth. J. Fluoride Chem., 115, 41-47. http://dx.doi.org/10.1016/S0022-1139(02)00003-9

Mufazzal, S. M., Moosa, H. S., \& Ahmed, M. (1999). Adsorption and thermodynamic characteristics of $\mathrm{Hg}(\mathrm{II})-\mathrm{SCN}$ complex onto polyurethane form. Talanta, 50, 625-634. http://www.ncbi.nlm.nih.gov/ pubmed/18967753

Nyananyo, B. L., Gijo, A. H., \& Ogambe, E. N. (2007). The Physico-chemistry and Distribution of Water Hyacinth (Eichhornia cressipes) on the river Nun in the Niger Delta. J. Appl. Sci. Environ. Manage., 11(3), 133-137. Retrieved from http://www.google.com.ng/url?sa=t\&rct=j\&q=\&esrc=s\&source=web\&cd= $1 \&$ ved $=0$ CB4QFjAA\&url=http $\% 3 \mathrm{~A} \% 2 \mathrm{~F} \% 2 \mathrm{Fwww}$.ajol.info\%2Findex.php\%2Fjasem\%2Farticle\%2Fdownl 
oad\%2F55158\%2F43630\&ei=eUH_U8gdy-jsBrz8gNgG\&usg=AFQjCNE257Z5z9jb9hNFoVrBz0NI3ryLZ A\&sig2=-TCT-Vk51ZjHDGIVt1NhQA\&bvm=bv.74035653,d.bGQ

Rajamohan, N. (2009). Equilibrium studies on sorption of an anionic dye onto acid activated water hyacinth roots. African Journal of Environmental Science and Technology, 3(11), 399-404. Retrieved from http://www.google.com.ng/url?sa=t\&rct=j\&q=\&esrc=s\&source=web\&cd=1\&ved=0CCEQFjAA\&url=http $\% 3 \mathrm{~A} \% 2 \mathrm{~F} \% 2 \mathrm{Fwww}$. researchgate.net\%2Fpublication\%2F228359748_Equilibrium_studies_on_sorption_of_ an_anionic_dye_onto_acid_activated_water_hyacinth_roots\%2Flinks\%2F0c96052 b6beb62401 b000000 \&ei $=8 \mathrm{UH} \_\mathrm{U} \_5 \mathrm{CK} 7 \mathrm{0} 7 \mathrm{AaQ1YC} 4 \mathrm{Dg} \&$ usg $=$ AFQjCNFtVdrsdRR_Q1EURfhw017-3DUPUQ\&sig2=xIlrse9QcW HdTf9-V2gFgg\&bvm=bv.74035653,d.bGQ

Sivaraj, R., Venckatesh, R., \& Gowri, S. G. (2010). Activated carbon prepared from Eichornia crassipes as an adsorbent for the removal of dyes from aqueous solution. Int J Eng Sci Technol, 2, 2418-2427. Retrieved from http://www.ijest.info/docs/IJEST10-02-06-15.pdf

Soni, M, Sharma, A. K., Srivastava, J. K., \& Yadav, J. S. (2012). Adsorptive Removal of Methylene Blue Dye from an Aqueous Solution using Water Hyacinth Root Powder as a Low Cost Adsorbent. International Journal of Chemical Sciences and Applications, 3(3), 338-345. Retrieved from http://bipublication.com/files/ IJChSA-V3I3-2012-1.pdf

Varghese, S., Vinod, V. P., \& Anirudhan, T. S. (2004). Kinetics and Equilibrium Characterization of Phenols Adsorption onto a novel Activated Carbon in water treatment. Indian J. Chem. Tech., 11, 825-833. http://nopr.niscair.res.in/handle/123456789/9543

\section{Copyrights}

Copyright for this article is retained by the author(s), with first publication rights granted to the journal.

This is an open-access article distributed under the terms and conditions of the Creative Commons Attribution license (http://creativecommons.org/licenses/by/3.0/). 